\title{
O alcoolismo, suas causas e tratamento nas representaçóes sociais de profissionais de Saúde da Família
}

\author{
| ${ }^{1}$ Luiz Gustavo Silva Souza, ${ }^{2}$ Maria Cristina Smith Menandro, \\ ${ }^{3}$ Paulo Rogério Meira Menandro I
}

Resumo: As ciências da saúde definem o alcoolismo como síndrome multifacetada. Para o tratamento, diretrizes preconizam a adoção do paradigma de redução de danos e o importante papel da Atenção Primária à Saúde (APS) junto aos problemas com o álcool. Esta pesquisa teve por objetivo compreender representaçōes sociais do alcoolismo construídas por profissionais de APS, atuando em Unidades de Saúde da Família (USF). Foram realizadas entrevistas semiestruturadas com 40 profissionais de nível superior, que atuavam em 11 diferentes USF de um município do Sudeste do Brasil, e análise de conteúdo temática. Destacam-se os seguintes resultados: os profissionais objetivavam o alcoolista como usuário que não demandava cuidado para essa condição e/ou que ameaçava o funcionamento das USF; consideravam causas sociais e psicológicas como as mais importantes; não mencionaram o conceito de redução de danos, nem fluxos bem definidos de tratamento. A discussão indica que a atribuição causal e o campo representacional próprio às representações sociais contribuíam para ancorar o alcoolismo como "chaga" da pobreza. As USF eram tidas simultaneamente como importantes e como impotentes frente ao alcoolismo. Conclui-se que a implantação de estratégias para problemas com o álcool na APS deve atentar para relações intergrupais entre profissionais e usuários. 
A palavra "alcoolismo" surgiu e se estabeleceu na Europa do século XIX, quando transformações sociais promoviam a higienização das cidades, a industrialização e o nacionalismo, com as respectivas demandas por disciplina, majoração econômica e adestramento político das massas. Nesse contexto, o consumo "excessivo" de álcool pelas populações foi tratado como grave "praga", capaz gerar desordem, desagregação, promiscuidade, indisciplina, ameaçando a produtividade, o Estado-nação e até a integridade da espécie humana. O alcoolismo foi, durante cerca de um século, associado à "degenerescência", à degradação física, psicológica e moral que, na mentalidade da época, poderia ser adquirida e transmitida à prole (SOURNIA, 1986).

A partir do século XVII, com o consumo massificado de bebidas alcoólicas e, em especial, de bebidas destiladas, mais potentes, consolidou-se a crença de que o consumo excessivo (a "intemperança”) constituía uma espécie de "pecado social”, contrário aos ideais da sociedade moderna e higienizada que nascia. Associaçóes de Temperança, preocupadas com a disseminação do álcool, surgiram nos EUA no início do século XIX (GOLD; ADAMEC, 2010; SOURNIA, 1986).

Especialmente nos Estados Unidos, no século XIX, a "luta" contra o consumo excessivo se caracterizou pela mistura de "muita moral a uma parte de religião e a um pouco de medicina" (SOURNIA, 1986, p. 52). Nesse país, ao longo do século XIX, foram criadas várias Associações de Temperança, como os Washingtonians, The Good Templars e a Woman's Christian Temperance Union. É interessante destacar que as reuniōes dos Washingtonians eram similares ao que veio a se instituir posteriormente nos Alcoólicos Anônimos. Referências religiosas nos nomes dessas associações ilustram a percepção de necessidade de luta do "bem contra o mal". Falava-se em "cruzada" contra o álcool (que assumiu, portanto, o papel de "demônio", de "inimigo") (GOLD; ADAMEC, 2010; SOURNIA, 1986).

Como mostram Conrad e Schneider (1992), nas sociedades industrializadas, o desvio foi tradicionalmente compreendido como pecado, crime e/ou doença, sendo essas categorias, de certa forma, intercambiáveis e sobrepostas. Com o "consumo crônico de álcool" não foi diferente. Em meados do século XX, quando enfraqueceram os discursos sobre a degenerescência, afirmou-se fortemente a maneira médica de apreensão do fenômeno. 
O trabalho de E. M. Jellinek foi emblemático nesse sentido, decretando o alcoolismo como doença sui generis. Sua causa seria fisiológica e identificável, própria a alguns indivíduos, e levaria à perda do controle volitivo e comportamental frente ao álcool inevitavelmente a partir do primeiro gole. Nessa formulação, o "alcoolismo como doença", a patologia seria grave, progressiva, constituída de fases bem delimitadas e a única solução seria a abstinência definitiva. A fundação e a grande difusão dos Alcoólicos Anônimos (AA) contribuíram para a consolidação da hipótese da doença. Os AA tiveram influência decisiva na obra e no pensamento de E. M. Jellinek e é possível afirmar que foram o principal agente de medicalização do alcoolismo, antes mesmo dos médicos (CONRAD; SCHNEIDER, 1992).

Embora não tenham assumido definição clara sobre o alcoolismo, os AA se referiram ao fenômeno como "alergia", metáfora adequada ao paradigma médico. Adotaram e difundiram as ideias de que "um alcoólico será sempre um alcoólico", de que a única solução para o problema é a abstinência total e definitiva e de que seu tratamento deve incluir grupos calcados na espiritualidade e nos depoimentos pessoais. O primeiro dos famosos “doze passos" faz referência à perda do controle sobre a bebida. Essas ideias encontraram pronunciada sedimentação no senso comum (CONRAD; SCHNEIDER, 1992).

Em princípio, é possível pensar que a medicalização poderia funcionar como apoio para questionar a estigmatização dos "doentes”. De fato, a abordagem médica ou "de saúde", que funcione com base na clínica ampliada (CAMPOS, 2003) promovendo autonomia e corresponsabilização, pode favorecer a percepção da "pessoa" sem reduzi-la à sua doença. Entretanto, o processo de medicalização geralmente funciona em prol da heteronomia e do controle social dos desvios, mantendo sobre eles, como elementos mais ou menos implícitos, as significações de pecado e de crime (CONRAD; SCHNEIDER, 1992). Daí o parentesco da medicalização com o higienismo, com o controle e a estigmatização das classes populares (MATOS, 2000). Nas classes populares, os desvios são percebidos como mais graves e mais numerosos, pois essas sofrem a imputação de rótulos operada pelos grupos que dominam recursos físicos e simbólicos (CONRAD; SCHNEIDER, 1992). Enraizada nos sistemas culturais, encontra-se a ideia de que o alcoolismo implica, "ao lado" da doença, ser mau homem, má mulher, mau trabalhador, má trabalhadora, mau marido, má esposa, etc. - ou seja, implica julgamentos morais. 
No Brasil, assim como em muitos países, o alcoolismo foi alvo do discurso médico-higienista. No início do século XX, campanhas antialcoólicas foram direcionadas essencialmente aos homens de classe popular. As campanhas se baseavam fortemente em estereótipos de gênero: o homem deveria ser o "trabalhador-provedor" e a mulher deveria ser a "perfeita dona-de-casa" que garantiria um lar aconchegante para o marido e os filhos. $\mathrm{O}$ alcoolismo era apresentado como a antítese desses valores, associado à vagabundagem e ao crime, caminho para a destruição da família e para a animalização (MATOS, 2000).

Barbiani et al. (2014) também destacam que a medicalização incidiu tradicionalmente sobre as famílias empobrecidas. Seu caráter eugênico subsiste na atualidade e novas características emergem, tais como a responsabilização das famílias de classe popular pela saúde e pelo meio ambiente e o incentivo à lógica de mercado e ao consumo de soluçôes de saúde. Permanece marcante a convergência entre ideais de saúde e a moralidade hegemônica.

Em estudo recente, Alzuguir (2014) mostra que, nas concepções de alcoolistas usuários de um serviço hospitalar, coexistem e interligam-se formas médicas e moralizantes de compreender o alcoolismo e de lidar com ele. A dimensão moralizante, que implica prescrições sobre como ser um "bom homem" e uma "boa mulher", fica claramente evidenciada por meio do sentimento de vergonha expresso pelos usuários, ligado especialmente à recaída e à internação hospitalar.

Do pecado ao crime, da criminalização à doença, a sequência de significações associadas ao alcoolismo não parou por aí. Nas décadas finais do século XX, ele foi reinterpretado pelas ciências da saúde como condição polimorfa. Não mais como doença sui generis bem delimitada, mas como conjunto de sintomas, ou seja, "síndrome de dependência do álcool". Fala-se de "problemas com o álcool", amplo espectro que inclui a noção de dégradé entre o consumo moderado, sem risco, e a dependência estabelecida, passando pela noção de "uso nocivo" (BERTOLOTE, 1997; FORMIGONI; MONTEIRO, 1997).

"Síndrome de dependência do álcool" e "uso nocivo de álcool" são categorias descritas no manual da Organização Mundial da Saúde (OMS), a Classificação Internacional das Doenças, em sua décima versão. Utiliza-se a categoria de uso nocivo para descrever quadros em que se verificam danos físicos, mentais ou sociais ligados de forma inequívoca ao consumo de álcool sem que haja a presença da dependência. $\mathrm{O}$ diagnóstico da síndrome de dependência, por sua vez, é feito com 
a constatação de presença de três ou mais dentre seis critérios. Esses critérios não

incluem somente os sinais mais tradicionalmente associados à dependência como compulsão, tolerância e síndrome de abstinência. Como consequência, situações variadas e singulares podem ser classificadas como síndrome de dependência do álcool (BERTOLOTE, 1997; ROTGERS; DAVIS, 2006).

Contemporaneamente, identificam-se quatro padróes de consumo de álcool: o consumo moderado, sem risco; o consumo arriscado, que tem o potencial de produzir danos; o consumo nocivo, que se define por um padrão constante de uso já associado a danos à saúde; e o consumo em binge, que diz respeito ao uso eventual de álcool em grande quantidade. $\mathrm{O}$ entendimento sobre a etiologia do alcoolismo é amplo, incluindo fatores biológicos, psicológicos e sociais (FORMIGONI; MONTEIRO, 1997; ROTGERS; DAVIS, 2006). A partir desse ponto de vista, mais recente, os sintomas e padróes de consumo podem variar consideravelmente e o alcoolista pode ter muitas "caras".

As atuais prescrições de tratamento são também bastante diferentes da ideia de "abstinência definitiva como única solução". Propõem-se soluções multifacetadas a problemas considerados multifacetados. Diretrizes nacionais e internacionais afirmam que a Atenção Primária à Saúde (APS) deve adotar estratégias permanentes de Triagem e Intervenção Breve (TIB), atuando em todo o espectro de problemas com o álcool e na própria cultura de consumo das bebidas em âmbito populacional. Casos de comprometimento mais severo com a substância devem ser encaminhados a centros de especialidade, que proponham estratégias estruturadas de assistência e sistemas de acompanhamento contínuo (focando prevenção de recaída, se for o caso). Para esses casos, prevê-se o recurso à internação para desintoxicação e a medicações que minimizem a compulsão e os sintomas de síndrome de abstinência (BRASIL, 2004, 2007; HEATHER; STOCKWELL, 2004).

O paradigma de redução de danos se afirma como possibilidade de trabalhar para melhorar a qualidade de vida e o autocuidado de usuários problemáticos de álcool, mesmo sem a prescrição da abstinência como objetivo primeiro ou último (ANDRADE; FRIEDMAN, 2006). No Brasil, os Centros de Atenção Psicossocial - álcool e drogas (CAPS-ad) são propostos como principal referência para o tratamento de alcoolistas, devendo embasar suas estratégias no paradigma de redução de danos (BRASIL, 2004). 
Estariam os profissionais de saúde adotando essas noções? Muitos estudos, feitos há várias décadas ou apenas há alguns anos, atestaram que profissionais de saúde continuam a estigmatizar o usuário percebido como alcoolista (CONRAD; SCHNEIDER, 1992; RONZANI; FURTADO, 2010). Kanno, Bellodi e Tess (2012) constataram que profissionais de Saúde da Família percebem a demanda "médico-social" que lhes é dirigida como complexa e difícil. Percebem, em seu cotidiano de trabalho, sobrecarga e desvalorização e relatam experimentar frequentemente sentimentos de frustração e de impotência, especialmente para tópicos como tráfico de drogas, violência intrafamiliar e alcoolismo.

Para além da estigmatização, como profissionais de saúde constroem coletivamente a realidade do alcoolismo e dos usuários alcoolistas? Que conjuntos de crenças, imagens e teorias eles mobilizam para enxergar o fenômeno, suas causas e seus possíveis tratamentos? Em que campo representacional (MOSCOVICI, 1961) eles ancoram esses objetos?

O objetivo do presente estudo foi fornecer possíveis respostas a essas questôes, investigando representações sociais do alcoolismo construídas por profissionais de Saúde da Família. A questão é especialmente pertinente tendo em vista a importância conferida à Atenção Primária à Saúde na atenção aos problemas com o álcool (AASLAND; NYGAARD; NILSEN, 2008; BRASIL, 2004, 2007; HEATHER; STOCKWELL, 2004) e da importância da Estratégia Saúde da Família como ordenadora da APS brasileira (BRASIL, 1998).

\section{Fundamentação teórica}

Representações sociais são sistemas de conhecimentos, crenças e imagens, construídos de forma coletiva, compartilhados por grupos sociais, e que funcionam como teorias de senso comum para orientar práticas sociais (JODELET, 1999; MOSCOVICI, 1961; 2007). São compostas por três dimensões: a atitude (predisposição avaliativa) dirigida ao objeto de representação; as informações difundidas sobre o objeto de representação nos grupos sociais envolvidos e o campo representacional, conjunto de objetos associados ao objeto de representação, no bojo do qual este último ganha significação (MOSCOVICI, 1961).

Representações sociais são construídas ativamente por sujeitos e grupos, por meio de dois processos sociocognitivos, objetivação e ancoragem. A objetivação é o processo de seleção, organização e naturalização de ideias e imagens que 
fornecem uma figura concreta a um conceito abstrato, permitindo enxergá-lo no

mundo. A ancoragem é o processo de classificação do objeto de representação em um conjunto preexistente de crenças e significações (MOSCOVICI, 1961; 2007). A função geral das representações é tornar familiar o que pertence ao domínio do desconhecido, construindo a realidade simbólica objetiva-subjetiva do fenômeno (as representações não são apenas cognições sobre os objetos, mas também os objetos eles mesmos, JODELET, 1999). Apresentam as funções específicas de permitir e promover a comunicação no interior dos grupos sociais que as produzem; orientar e justificar práticas em relação aos objetos de representação; construir ou reforçar identidades sociais (ABRIC, 1994; JODELET, 1999; MOSCOVICI, 2007).

Oliveira (2011) destaca que parte expressiva do campo das ciências da saúde vem buscando superar a restrição ao paradigma biomédico, valorizando fatores psicológicos, sociais e psicossociais da produção da saúde. A autora constata a adequação da Teoria das Representações Sociais a esse propósito, uma vez que valoriza os saberes de senso comum e seu diálogo com o conhecimento técnicocientífico. A autora defende que as "necessidades de saúde" devem ser entendidas em seu contexto relacional e cultural, a partir dos significados, crenças e valores atribuídos pelos atores em questão aos fenômenos de saúde e doença.

A discussão remete ao conceito de representação profissional. Pesquisadores definem a representação profissional como um tipo específico de representação social, que não é nem conhecimento científico, nem de senso comum. Tratase de uma forma específica de conhecimento, elaborada coletivamente por categorias profissionais sobre objetos com os quais têm que lidar no cotidiano. As representações profissionais cumprem suas funções, dentre elas, contribuir para definir a realidade, permitir a comunicação, orientar condutas e contribuir para a construção da identidade, no contexto específico da atuação profissional (RATINAUD, 2009).

\section{Método}

Foram entrevistados 40 profissionais de 11 Unidades de Saúde da Família (USF), distribuídos igualmente quanto a gênero (20 mulheres, 20 homens) e quanto à categoria profissional (20 médicos e 20 não médicos). Essa distribuição teve apenas o objetivo de contemplar o mesmo número de participantes mulheres e homens, médicos e não médicos para os procedimentos qualitativos de coleta $\mathrm{e}$ 
1342 de análise de dados (evitando priorizar uma ou outra dessas categorias). Nesta análise, não serão feitas comparações entre os grupos. As USF localizavam-se em um município do Sudeste brasileiro, urbano, com cerca de 330 mil habitantes. Todos os profissionais trabalhavam em bairros de classe popular. Dentre os não médicos, encontravam-se nove enfermeiros, quatro dentistas, três assistentes sociais, duas farmacêuticas e duas psicólogas.

A pesquisa foi aprovada por comitê de ética de uma universidade federal. As diretrizes de ética em pesquisa foram respeitadas (Resolução no 466/12 do Conselho Nacional de Saúde), dentre elas a aplicação de Termos de Consentimento Livre e Esclarecido, que foram assinados por todos os participantes. A pesquisa foi realizada como parte de uma tese de doutorado, que contou com bolsa da Coordenação de Aperfeiçoamento de Pessoal de Nível Superior (CAPES, Brasil).

Dados sociodemográficos foram recolhidos com questionário específico. Foram realizadas entrevistas com os 40 participantes a partir de roteiro semiestruturado. O roteiro foi constituído por quatro questôes (ou questôes compostas) correspondentes a três dimensões de percepção sobre o fenômeno, como descreve o quadro 1. Seguindo o caráter semiestruturado da entrevista, o pesquisador fez essas questōes a todos os participantes, mas não se ateve a elas, elaborando comentários e novas questōes em cada ocasião, para estabelecer empatia e para explorar aspectos interessantes das falas produzidas.

\section{Quadro 1. Roteiro semiestruturado aplicado nas entrevistas}

\begin{tabular}{|l|l|}
\hline \multicolumn{1}{|c|}{$\begin{array}{c}\text { Dimensóes } \\
\text { investigadas }\end{array}$} & \multicolumn{1}{c|}{ Questôes } \\
\hline $\begin{array}{l}\text { O fenômeno do } \\
\text { alcoolismo na } \\
\begin{array}{l}\text { Unidade de Saúde } \\
\text { da Família }\end{array}\end{array}$ & $\begin{array}{l}\text { 1. Como o alcoolismo aparece na Unidade de Saúde? Como a } \\
\text { equipe lida com os casos? }\end{array}$ \\
$\begin{array}{l}\text { 2. Você já precisou atender profissionalmente alguém que estava } \\
\text { alcoolizado naquele momento? Como foi a experiência? Que } \\
\text { sentimentos associa a esse atendimento? }\end{array}$ \\
\hline $\begin{array}{l}\text { Atribuição de } \\
\text { causas }\end{array}$ & $\begin{array}{l}\text { 3. Que fatores você destaca como importantes para entender } \\
\text { porque alguém se torna alcoolista? }\end{array}$ \\
\hline $\begin{array}{l}\text { Tratamentos } \\
\text { preconizados }\end{array}$ & $\begin{array}{l}\text { 4. Que tipo de tratamento você acredita que deve ser adotado para } \\
\text { pessoas que desenvolveram alcoolismo? }\end{array}$ \\
\hline
\end{tabular}


As entrevistas foram transcritas integralmente e o material foi tratado com análise de conteúdo temática (BARDIN, 1977; POPE; ZIEBLAND; MAYS, 2005). Esse procedimento se iniciou com a leitura flutuante das entrevistas e a identificação preliminar dos principais núcleos de sentido (temas) mencionados como respostas às questôes. As dimensōes citadas no quadro 1 serviram como categorias preliminares. $\mathrm{O}$ procedimento de comparação constante foi utilizado para delimitar os temas, tornando-os mais abrangentes ou restritivos (POPE; ZIEBLAND; MAYS, 2005). O conjunto dos núcleos de sentido produzidos pelos profissionais foi interpretado segundo a Teoria das Representações Sociais (JODELET, 1999; MOSCOVICI, 2007).

\section{Resultados}

A idade dos participantes variou de 26 a 61 anos, com média de 36,4 anos (DP $=8,7)$. O tempo de profissão variou de três a 35 anos, com média de 11,1 anos $(D P=8,7)$. O tempo de trabalho em APS, variando de um ano e meio a 25 anos, apresentou média de 6,3 anos $(D P=5,8)$. Tratou-se, portanto, de grupo heterogêneo quanto à idade, tempo de profissão e de trabalho em Atenção Primária ou Unidade de Saúde da Família. Dentre os entrevistados, 67\% declararam usar bebidas alcoólicas (33\% declararam-se abstinentes), 52\% afirmaram ter caso de alcoolismo na própria família (pais, irmãos, tios, primos ou cunhados). A maior parte declarou pertencer à classe média (70\%) ou média-alta (22\%).

Neste tópico (Resultados), trechos entre aspas referem-se sempre a expressões ou falas literais dos participantes. Os destaques dos autores são grafados com itálico. A tabela 1 apresenta um resumo dos resultados obtidos por meio da análise de conteúdo temática. Nessa tabela, são expostos os temas citados pelos profissionais como resposta às questôes da entrevista semiestruturada. As porcentagens foram calculadas em relação ao número total de participantes $(\mathrm{N}=40)$. 

resposta às questóes da entrevista semiestruturada

\begin{tabular}{|c|c|c|}
\hline Questóes e Temas & $n$ & $\%$ \\
\hline \multicolumn{3}{|l|}{ Como o alcoolismo aparece na Unidade de Saúde? } \\
\hline Alcoolista com consequências do alcoolismo ou quadros associados & 24 & 60 \\
\hline Alcoolista em intoxicação aguda, possivelmente agressivo & 19 & 47 \\
\hline Familiar do alcoolista demanda atendimento para o usuário ou para si & 11 & 27 \\
\hline A demanda para tratamento do alcoolismo dificilmente ocorre & 9 & 22 \\
\hline Alcoolistas no bairro e em visitas domiciliares & 8 & 20 \\
\hline Usuário em busca de tratamento para o alcoolismo & 5 & 12 \\
\hline Profissional de saúde alcoolista (um agente de saúde) & 2 & 5 \\
\hline \multicolumn{3}{|l|}{ Como a equipe lida com os casos? } \\
\hline Os profissionais adotam procedimentos técnicos & 37 & 92 \\
\hline Os profissionais têm preconceito/ praticam discriminação & 13 & 32 \\
\hline Os profissionais não sabem o que fazer, não estão preparados & 8 & 20 \\
\hline A equipe lida bem com os casos & 3 & 7 \\
\hline A equipe não pratica discriminação & 2 & 5 \\
\hline \multicolumn{3}{|l|}{ Que fatores são importantes para explicar o alcoolismo? } \\
\hline Fatores genéticos/ "a genética” (menções literais) & 24 & 60 \\
\hline Fatores sociais/ “o social” (menções literais) & 38 & 95 \\
\hline Fatores ou problemas familiares/ "família desestruturada" & 21 & 52 \\
\hline Cultura da comunidade & 10 & 25 \\
\hline Dificuldades financeiras & 9 & 22 \\
\hline Estímulo dos pares & 9 & 22 \\
\hline Estímulo das propagandas de televisão & 5 & 12 \\
\hline Falta de um (bom) emprego & 4 & 10 \\
\hline Falta de alternativas de lazer & 2 & 5 \\
\hline
\end{tabular}


Falta de valores

Falta de reconhecimento social

Violência

Fatores psicológicos/ “o psicológico” (menções literais)

Fuga de problemas

Hábito/ comportamento condicionado

Falta de autoestima

Falta de perspectivas para o futuro

$3 \quad 7$

Fraqueza psicológica

Dificuldade de se expressar

$\begin{array}{ll}3 & 7 \\ 1 & 2\end{array}$

Que tipo de tratamento deve ser adotado?

Medicação/ tratamento médico, psiquiátrico

Tratamento psicológico

Tratamento multiprofissional

Aconselhamento/ acompanhamento da família

$15 \quad 37$

Alcoólicos Anônimos/grupos de mútua ajuda

$13 \quad 32$

Atendimento em serviço social

$10 \quad 25$

Visita domiciliar/ busca ativa

$10 \quad 25$

Internação para desintoxicação

O usuário tem que ter força de vontade

820

820

Conscientização/ o usuário tem que se reconhecer doente

$6 \quad 15$

Outras especialidades médicas (gastroenterologia, p. ex.)

Terapia ocupacional

$3 \quad 7$

Apoio da Equipe Matricial

Atendimento em enfermagem

A religião pode ser importante

Encaminhamento ao trabalho 
Todos os profissionais entrevistados reconheceram maneiras pelas quais o alcoolismo "aparece" na Unidade de Saúde. Alguns acrescentaram que o alcoolismo "aparece muito". A forma mais frequente de descrever a chegada do usuário alcoolista foi por sua associação a comorbidades ou consequências do alcoolismo. Em consultas individuais, por exemplo, o usuário vinha se queixar de problemas gástricos e o profissional o percebia como alcoolista. Esse também era o caso de usuários que participavam de grupos de controle de diabetes ou hipertensão. Além dessas referências biomédicas, profissionais citaram problemas de relação interpessoal como quadros associados ao alcoolismo: os usuários chegavam por causa de "problemas sociais, conflitos familiares, fim de casamento".

Essa forma de enxergar o fenômeno esteve associada à ideia de que a demanda específica para tratamento do alcoolismo dificilmente ocorria. Uma assistente social afirmou: "ele raramente vem aqui falando 'eu quero uma consulta pra eu deixar de beber"'. Há duas ideias interessantes nessa fala, que foram repetidas por outros profissionais: 1) ao falar do alcoolista, a pessoa imaginada foi "ele", ou seja, um homem; 2) o tratamento demandado foi traduzido como "deixar de beber". Sete profissionais mencionaram explicitamente a ideia da abstinência como o objetivo terapêutico por excelência.

Segundo profissionais, por vezes o alcoolista não aparecia diretamente na Unidade, mas sim pelo discurso dos outros. "Familiares, parentes próximos, vizinhos" pediam a ajuda da USF para tratar do alcoolista ou de si mesmos (casos de esposas de alcoolistas, por exemplo, "deprimidas por causa disso", como afirmou uma médica).

Em outras ocasiões, eles não eram percebidos na Unidade propriamente, mas nos trabalhos de campo e nas visitas domiciliares. Um enfermeiro contou: "por volta de $15 \mathrm{~h} 30 \mathrm{~min}$ eu encontrei vários pacientes lá, vários senhores lá no morro, completamente bêbados. [...] quando chega aqui na US, você não vê muito. Você percebe né, que tem problema com álcool. Mas assim, lá em cima do morro isso é bem evidente". Interessante notar a associação das expressões "problema com o álcool" (termo mais afeito às concepções técnico-científicas sobre o alcoolismo) e "Unidade de Saúde" e, por outro lado, das expressões "bêbados" e "morro" (expressões coloquiais que indicam a construção de um saber de senso comum). Na fala do profissional, é no "morro" que o alcoolismo 
é claramente visível, como se fosse ali seu lugar natural ("em cima do morro isso é bem evidente"). Mais adiante, a análise dos dados indicará que as representações sociais investigadas incluíam a ideia do bairro de classe popular como lugar por excelência do alcoolismo.

Outra forma frequente de descrever como o alcoolismo aparece na USF foi fazer referência ao alcoolista em intoxicação aguda, possivelmente agressivo. Ao contrário do alcoolista que aparece pela comorbidade, o alcoolista em intoxicação aguda não se adéqua à rotina da Unidade. Ele quebra essa rotina com sua presença percebida como incômoda e ameaçadora. Afirmou uma farmacêutica:

Todo mundo já sabe que é o fulano, que ele geralmente chega aqui com... malcheiroso, né, falando embolado, que ninguém consegue compreender, às vezes causando tumulto, às vezes exigindo alguma coisa, e acaba atrapalhando o fluxo da Unidade. Então, ele acaba sendo mal visto por todos os profissionais que têm contato.

Os adjetivos "agitado", "agressivo", "exaltado" e "malcheiroso" foram utilizados pelos entrevistados para caracterizar esse alcoolista. Algumas expressóes chamaram a atenção. Um médico contou que outros profissionais lhe diziam eventualmente "Aquele paciente bêbado enjoado está aí de novo, doutor”. Um enfermeiro se referiu a uma senhora que teria chegado à Unidade "tocando o maior barraco, xingando todo mundo". Também nessas falas, fica evidente a distância do vocabulário técnico-científico. $\mathrm{O}$ usuário não é descrito como alcoolista, mas como "bêbado enjoado". Seus sintomas não são interpretados como crise relacionada a certo transtorno psiquiátrico, mas como confusãotransgressão ("barraco”).

De acordo com alguns profissionais, o alcoolista em intoxicação aguda frequentemente exigia atendimento imediato, negava-se a ouvir orientaçōes e, muitas vezes, ia embora sem aguardar o atendimento. Houve alguns interessantes relatos de práticas. Um dentista descreveu caso em que teve que fingir o atendimento, uma vez que a condição de alcoolização do usuário impedia a realização de procedimentos: "lidar com bêbado, cê tem que enrolar o sujeito, né". Uma médica se referiu ao atendimento de "um outro paciente que foi bastante agressivo" e contou:

Foi horrível! E eu vou te falar a verdade, eu atendi ele com a porta [do consultório] aberta. Porque eu não sabia qual ia ser a reação dele. [...] Eu fiquei até com medo, eu falei: “esse cara aí vai me bater!”. E aí [...] eu não consegui nem consultar ele direito, assim, fazer um exame físico, né. Eu fiquei com medo. 
Quando responderam ao segundo conjunto de questôes descrito no quadro 1 (atendimento ao usuário alcoolizado e sentimentos associados), os profissionais voltaram a se referir a esse tema do alcoolista em intoxicação aguda (o "bêbado enjoado" que chega "tocando o maior barraco"). Todos os profissionais disseram já ter tido a experiência de atender a usuário que estava, no momento do atendimento, embriagado.

Para falar sobre a presença desses usuários, profissionais recorreram a abundantes conteúdos figurativos (icônico-sensitivos). Expressões utilizadas por nove profissionais foram assim condensadas:

Cheiro de cana horrível; mendigos; malcheiroso; não toma banho nem nada; odor insuportável, cospe, vomita, dentro do banheiro [da Unidade]; bêbado chato; bêbado miserável [essas duas últimas expressões foram mencionadas como reproduçôes da fala de outros profissionais]; caras [que] ficam tomando cachaça o dia inteiro; sempre tá bêbado; o hálito é muito desagradável; odor horrível, fedendo, gritando; vêm pedir uma coisa que nem sabe o que estão pedindo; não conseguia nem falar direito; sinais de embriaguez ou de ressaca; pessoa que está cheirando mal, que não consegue articular frases, não consegue falar direito; desagradáveis.

Embora não tenha havido menções diretas ao nojo, essas expressões permitem entrever sua presença. $\mathrm{O}$ sentimento mais frequentemente associado ao atendimento do usuário embriagado foi a impotência (27\%). Profissionais também citaram os sentimentos de frustração (17\%), preocupação (15\%) e impaciência/ intolerância (12\%).

Os participantes responderam também à questão sobre como as equipes lidavam com os casos de alcoolismo nas USF. Quase todos os participantes mencionaram procedimentos técnicos que eram ou poderiam ser adotados frente aos casos: formas de acolhimento, acompanhamento, tratamento e encaminhamento (hidratação no caso de intoxicação aguda, realização de exames, prescrição de medicação, discussões em reuniōes de equipe, etc.). Foi possível notar grande heterogeneidade nas menções terapêuticas e na forma de falar sobre elas, o que indica que não havia fluxos claros de atendimento ao alcoolismo no pensamento social do grupo.

Participantes disseram também que, frente a casos de alcoolismo, os profissionais têm preconceito e/ou praticam discriminação. "'poxa vida... você veio aqui fazer o que se você está bêbado?”, disse um médico, reproduzindo o que acreditava ser o pensamento de colegas. Houve numerosas menções ao "despreparo" de profissionais para lidar com o alcoolismo, como na fala de uma 
enfermeira: "A gente tem uma dificuldade de formação mesmo [...] pra lidar com um usuário [...] que tem problema de drogadição [...] E a gente é muito mais preparado pra lidar com doença orgânica”.

É interessante notar a contraposição feita pela profissional entre a "drogadição" (incluindo o alcoolismo) e a "doença orgânica”. Essa contraposição indica que os profissionais não explicavam o alcoolismo hegemonicamente pela fisiologia. Chegou-se exatamente a esse resultado com a análise de conteúdo das respostas dadas à questão sobre as causas do fenômeno. Os participantes mencionaram "a genética", as causas ou fatores genéticos, mas sempre como codeterminantes e via de regra como pano de fundo para as causas percebidas realmente como fundamentais: os fatores sociais e psicológicos. Diferentemente da "genética", esses outros fatores mereceram elaborações mais detalhadas e foram complementados por qualificativos como: "mais", "principalmente", "mais importante", "primordial”, "primeiramente", "principais", “o grosso mesmo", como na fala de um médico: "existe alguma predisposição genética [...]. Mas, o grosso mesmo eu acho que é psicológico e social. Dificuldade pra lidar com problemas da vida, valores aprendidos".

Dentre os fatores psicológicos, destacou-se a hipótese da "fuga" utilizada, por exemplo, por uma médica: "pra esquecer dos problemas ele se afoga no copo de cerveja, né. [...] Uma fuga. Seria uma fuga” (note-se a interessante imagem de afogamento do alcoolista, que pode implicar esconder-se com a submersão ou matarse). A hipótese da "fuga" possivelmente subentende que o alcoolista seja fraco, covarde ou preguiçoso para enfrentar problemas, já que o senso comum ensina que todos têm problemas. A "fraqueza" psicológica foi mencionada diretamente em três entrevistas, como no seguinte exemplo: "Tem pessoas que têm uma personalidade mais fraca, têm maior facilidade de se tornar dependente de certas drogas". O "hábito", a falta de "autoestima" ou de "perspectivas de futuro" foram outros fatores psicológicos mencionados como causas do alcoolismo.

No discurso do grupo investigado, o tema que mais se destacou como explicação do alcoolismo foi aquele dos "fatores sociais". Os "fatores sociais" ou "o social" (adjetivo substantivado) foram mencionados de forma literal em 95\% das entrevistas. Havia algo "no social" dos usuários alcoolistas que chamava a atenção dos profissionais de forma quase onipresente. Características familiares e/ou a "família desestruturada" foram o desdobramento mais comum dos 
fatores sociais. O tema foi citado na fala de uma médica: "sabe, [com] a família desestruturada, é muito fácil você cair na tentação".

Em um quinto das entrevistas, "o social" foi traduzido como dificuldades financeiras. Um médico expressou a noção de família pobre e desestruturada com especial clareza:

E hoje meio que... principalmente na população socioeconomicamente prejudicada, que não tem dinheiro, você não conhece nem o papel da mãe... ou a criança fica com vizinho, ou fica com a avó, aí perde o respeito, não tem respeito.

O tema da cultura da comunidade, referido diretamente em parte das entrevistas, pode ser central para entender como os profissionais concebiam a causalidade social do alcoolismo. Os profissionais falaram sobre uma "cultura" própria às pessoas empobrecidas (referidas como "população socioeconomicamente prejudicada", "pessoal de classe social mais baixa”, "esse povo que mora aqui em cima", "povo [...] no morro"), cultura que incluiria o uso excessivo de álcool, ora como forma de lidar com situações de precariedade, ora como característica intrínseca desse estilo de vida diferente. A fala de uma enfermeira foi especialmente eloquente nesse sentido. A profissional mencionou seu sentimento de estranhamento quanto ao "povo bebendo", à "música alta", à "mistura" que ela percebia "no morro":

A própria comunidade assim... Dia de semana a gente vai... vai no morro, e eles estão fazendo churrasco e bebendo. Segunda, terça, quarta. Não tem muito dia não, assim, sabe. Quando você tá trabalhando... Em plena segunda-feira, dez horas da manhã,o povo bebendo com música alta lá no morro, sabe. Churrasco... [...] E, assim, grande número de desempregados, muitas meninas jovens, mulheres também mais velhas. Assim, é uma mistura, né... crianças no meio e tal. É uma coisa meio que normal, assim.

Dizer que o alcoolismo e os usuários alcoolistas eram percebidos principalmente em relação ao tema da cultura da comunidade não significa dizer que os profissionais falhavam em reconhecer o alcoolismo em outras classes e ambientes sociais (essa ideia foi citada explicitamente por seis participantes). Antes, significa dizer que, na percepção dos profissionais, o alcoolismo que aparecia nas unidades de saúde era um alcoolismo específico. Aquele alcoolista não era qualquer alcoolista, mas sim, um usuário de classe popular apreendido por uma série de outros filtros sócio-cognitivo-afetivos.

Em resposta à questão sobre o tipo de tratamento que deve ser adotado, os temas mais citados pelos profissionais foram o tratamento médico/psiquiátrico 
e o tratamento psicológico (65\%). Entretanto, chama a atenção a variedade de categorias profissionais mencionadas como importantes para tratar o alcoolismo, assistentes sociais, outras especialidades médicas, terapeutas ocupacionais, enfermeiros. O tema do tratamento multiprofissional foi evocado diretamente em quantidade expressiva de entrevistas (42\%).

Alguns temas remetiam mais claramente ao nível de Atenção Primária à Saúde, como o aconselhamento e o acompanhamento de famílias, as visitas domiciliares e a busca ativa, o apoio da equipe matricial, ${ }^{1}$ o encaminhamento ao trabalho e o aconselhamento dos colegas de trabalho do alcoolista. Trata-se de conjunto de atividades que pressupooe a proximidade e o caráter longitudinal da Atenção Primária, em seu objetivo ampliado de ultrapassar o curativismo e agir sobre estilos de vida. ${ }^{2}$

Outros temas evocavam outros níveis de atenção à saúde, como a referência às especialidades médicas e à necessidade de internação para desintoxicação. Foram citados serviços como o pronto-atendimento e o hospital geral. Cabe destacar a alta frequência de menções diretas ao CAPS-ad do município (65\%). Isso indica que esse serviço foi incorporado como referência importante para a temática em meio aos profissionais pesquisados. Pode ser também indício de que os profissionais viam no CAPS-ad um alívio para sua responsabilidade frente aos usuários, baseados na ideia que, afinal de contas, o alcoolismo seria problema do CAPS-ad.

Mas as respostas não incluíram apenas os serviços de saúde. Nota-se a presença de entidades extrassanitárias como a religião e os Alcoólicos Anônimos/grupos de mútua ajuda, estes últimos citados em cerca de um terço das entrevistas. As ideias de que o usuário tem que ter força de vontade e tem que se conscientizar de que está doente também foram frequentes no discurso dos participantes.

No que diz respeito às percepções sobre o tratamento, ressalta-se a quantidade e heterogeneidade dos temas citados, que incluíram o sistema de saúde, a família, a religião, grupos de mútua ajuda e a força de vontade. Em associação a essa heterogeneidade de temas, foi possível verificar que não havia, no pensamento social do grupo, um fluxo de atendimento bem definido para os usuários alcoolistas. É importante destacar que a expressão "redução de danos" foi citada de forma literal em apenas duas entrevistas e, nas duas ocasiōes, para se referir en passant a agentes de redução de danos que atuavam no município, ou seja, sem se referir efetivamente ao conceito de redução de danos. 


\section{Discussão}

A pesquisa investigou representações sociais construídas por profissionais brasileiros de Saúde da Família sobre o alcoolismo, incluindo concepçôes sobre o fenômeno, suas causas e seu tratamento. Uma das questôes de partida foi se essas concepçôes eram equivalentes aos conceitos utilizados atualmente pelas ciências da saúde para definir, explicar e abordar o alcoolismo. Pode-se responder negativamente a essa questão. Para falar sobre o fenômeno, os profissionais se utilizaram de ideias, crenças e terminologias que diferiam substancialmente de sua apreensão técnico-científica contemporânea.

É possível dizer que os profissionais tenderam a conceituar o alcoolismo como condição "tudo ou nada", consoante com a medicalização do fenômeno característica de meados do século XX, difundida pelos Alcoólicos Anônimos por E. M. Jellinek (CONRAD; SCHNEIDER, 1992). Encontraram-se as crenças, consolidadas historicamente com marcante participação dos AA, de que a abstinência total é a solução para o alcoolismo, de que seu tratamento deve incluir a frequência a grupos de mútua ajuda e de que a espiritualidade (a religião) pode ser importante.

Os profissionais não citaram a ideia de amplo espectro (dégradé) de problemas com o álcool (FORMIGONI; MONTEIRO, 1997). O conceito de "síndrome de dependência” (BERTOLOTE, 1997; ROTGERS; DAVIS, 2006) também não foi citado, nem sua aplicação variável aos casos singulares. $\mathrm{O}$ conceito ampliado de "problemas com o álcool" (HEATHER; STOCKWELL, 2004) não foi referido de forma sistemática, nem foram utilizados os conceitos de uso moderado, arriscado, nocivo ou em binge, comuns na literatura científica (ROTGERS; DAVIS, 2006).

As respostas sobre o tratamento que deve ser proposto ao alcoolismo indicaram que não havia, na percepção dos profissionais, protocolos compartilhados e permanentes. O uso da Triagem e Intervenção Breve, preconizado em escala global pela OMS como importante estratégia de APS (AASLAND; NYGAARD; NILSEN, 2008), não foi mencionado. Nas falas dos profissionais, o tratamento implicava abstinência. Destacou-se a ausência do uso do conceito de redução de danos, embora ele seja central para as diretrizes políticas atuais de atenção ao uso problemático de álcool e outras drogas (ANDRADE; FRIEDMAN, 2006; BRASIL, 2004). 
Houve, ao mesmo tempo, pontos de aproximação entre as concepções adotadas pelos profissionais investigados e o saber especializado contemporâneo. De forma semelhante a pesquisadores da área, os profissionais afirmaram que fatores biológicos, psicológicos e sociais devem ser levados em conta para compreender a etiologia do alcoolismo. Em consonância com diretrizes políticas e conhecimentos científicos atuais (BRASIL, 2004; ROTGERS; DAVIS, 2006), afirmaram que o tratamento do alcoolismo deve lançar mão de atenção multiprofissional, de recursos e serviços diversos, como atendimento médico, psicológico e de outras especialidades.

Mencionaram atendimentos típicos da APS (GIOVANELLA; MENDONÇA, 2008), como o acompanhamento contínuo de famílias, visitas domiciliares e suporte por parte de equipe matricial e citaram frequentemente o CAPS-ad como referência importante. A ideia de que se deve promover a motivação do usuário para o tratamento combina com a prescrição de corresponsabilização e participação ativa dos usuários (CAMPOS, 2003). A ausência de postura de competição com possíveis recursos extrassanitários, como a religião e os AA, também é condizente com diretrizes atuais (ROTGERS; DAVIS, 2006).

A comparação dos sentidos produzidos pelos profissionais com os conhecimentos especializados e com as diretrizes político-sanitárias para o setor pode ser importante para iniciativas de formação continuada. Mas é interessante frisar que a análise pretendida aqui não tem a intenção de enfatizar as ausências verificadas no discurso dos profissionais. Se considerado o conceito de "representação profissional" (RATINAUD, 2009), trata-se de analisar a positividade das representações, ao cumprir suas funçôes no contexto específico da atuação profissional. Busca-se compreender a positividade do saber que os participantes afirmavam, ou seja, sua articulação em teorias de senso comum, representações sociais, capazes de construir a realidade simbólica (subjetivaobjetiva) do fenômeno do alcoolismo e de explicá-la, orientando condutas.

Para empreender essa análise, é interessante ressaltar as formas pelas quais os profissionais objetivavam (MOSCOVICI, 1961; 2007) o alcoolismo, como eles selecionavam imagens, naturalizando-as, de maneira a enxergar o fenômeno no cotidiano. Algumas formas de objetivação se destacaram: o alcoolista que chegava à USF pelas comorbidades; o "bêbado" agressivo e ameaçador; o alcoolista apenas citado no discurso dos familiares; os "bêbados" espalhados 
pelo bairro e o alcoolista que procurava tratamento (evento visto como raro). A alternância dos termos "alcoolista" e "bêbado" visa destacar a duplicidade de registros cognitivos utilizados pelos profissionais para apreender o fenômeno, registros tanto técnico-científicos quanto de senso comum - polifasia cognitiva, segundo Moscovici (1961).

Destacou-se a ideia de que o alcoolismo "aparecia muito", mas que ele não se integrava de fato às rotinas das unidades. Essa ideia se relaciona com o tema dos usuários que eram percebidos como alcoolistas, mas que se dirigiam às unidades por outros motivos. Também se relaciona aos temas dos familiares que demandavam atendimento para o alcoolista ou para si e dos alcoolistas que eram percebidos "no morro", nas visitas domiciliares. No caso do alcoolista que chegava às unidades em intoxicação aguda, percebido como potencialmente desordeiro e agressivo, o usuário não só não se integrava às rotinas como as rompia de forma ameaçadora.

Essa forma de enxergar o fenômeno foi evocada com destaque para falar sobre os atendimentos em que o usuário se apresentava embriagado. Especialmente nesses casos, a atitude (predisposição avaliativa) dos profissionais em relação a esse usuário foi claramente negativa, com expressões como "malcheiroso", "vêm pedir uma coisa que nem sabe o que estão pedindo" e "desagradáveis". Foram identificados afetos negativos como impotência, frustração, preocupação, impaciência, intolerância e nojo.

Sem a pretensão de descrever a prática concreta dos profissionais, cujo acesso por meio de entrevistas é muito indireto, é possível afirmar que a direção hegemônica que essas representaçôes sociais do alcoolismo davam às práticas (função de orientação e justificação, ABRIC, 1994; JODELET, 1999) era a exclusão física ou simbólica do alcoolista das unidades. $\mathrm{O}$ atendimento do alcoolista em intoxicação aguda foi qualificado como muito difícil ou impossível. Os alcoolistas vistos nas visitas domiciliares e aqueles que compareciam às unidades pelas comorbidades eram percebidos como usuários que não demandavam atendimento para o alcoolismo.

Dentre as justificativas mencionadas para a escassez de atendimentos específicos para o alcoolismo, destacaram-se as percepções de que as equipes têm preconceito com esse tipo de usuário e de que não estão preparadas para atendêlo. Outro motivo plausível é a percepção de sobrecarga característica da APS, articulada com a ideia de que o alcoolismo seria problema exclusivo do CAPS-ad. 
Entretanto, foi possível identificar temas contra-hegemônicos, que indicaram possibilidades de transformação das representações (ABRIC, 1994). Mesmo que em pequeno número, profissionais afirmaram que as equipes lidavam bem com os usuários alcoolistas e/ou não praticavam discriminação. É interessante notar que a quase totalidade dos profissionais entrevistados (92\%) disse que, para lidar com o alcoolismo, as equipes adotavam ou poderiam adotar procedimentos técnicos. Isso pode indicar que, mesmo que não focalizadas na questão do alcoolismo, cuidado em saúde era oferecido aos usuários. O oferecimento desse cuidado independente da exigência de abstinência é característico do paradigma de redução de danos (ANDRADE; FRIEDMAN, 2006).

A percepção de escassez de atendimentos específicos para o alcoolismo também pode ser relacionada à causalidade atribuída ao fenômeno. As práticas de saúde são tradicionalmente centradas no saber biomédico, característica que persiste apesar das atuais diretrizes para o setor (SOUSA; HAMANN, 2009). As principais causas percebidas para o alcoolismo foram as sociais e psicológicas, percebidas como exóticas ao domínio biomédico. Trata-se da dificuldade para lidar com condiçôes diferentes da "doença orgânica", como afirmou uma das enfermeiras entrevistadas.

O campo representacional (MOSCOVICI, 1961) do alcoolismo incluiu ideias e imagens de objetos como: comorbidades, bares, morro, barracos (no sentido literal e figurado), população de rua, mendigos, familiares em sofrimento. As expressōes "fatores sociais", "fator social" e/ou "o social" foram citadas como causas do alcoolismo, de forma literal, por $95 \%$ dos participantes, o que é digno de nota tendo em vista o caráter semiestruturado das entrevistas. Verificou-se uma das características distintivas das representações sociais, a dualidade causal (MOSCOVICI, 1961; 2007). O fenômeno foi explicado não só por causas eficientes, os "fatores" etiológicos (sociais, psicológicos, genéticos), mas também causas fenomênicas: eles, os usuários, habitam "outra realidade”, constituem um exogrupo marcado pela precariedade material e moral.

Encontra-se aqui a tradicional ancoragem do alcoolismo como chaga da pobreza e da masculinidade (MATOS, 2000; SOURNIA, 1986). As representaçôes sociais do alcoolismo fazem equivaler o cambalear e a decadência (a queda) do alcoolista ao cambalear moral; a sarjeta do alcoolista à sarjeta social. Nas representações, o alcoolista é o homem - associado tradicionalmente 
à bebida, ao contrário da mulher (MATOS, 2000) - e é o homem pobre. A ideia, afeita ao saber técnico-científico, de que o alcoolismo é uma "doença multifatorial a ser tratada de forma integral" e a ideia, afeita aos saberes de senso comum, de que o alcoolismo é um "problema social, relacionado à pobreza das comunidades" encontravam-se condensadas de forma sincrética nas representações. Desse sincretismo decorria a percepção de que as USF eram simultaneamente importantes e impotentes frente ao alcoolismo; importantes quanto à "doença", impotentes quanto ao "problema social".

No que diz respeito à construção simbólica do álcool como objeto, pode-se inferir que as representações sociais investigadas permitiam afastar o eventual consumo de álcool dos profissionais daquilo que eles representavam como "alcoolismo", ou seja, permitiam construir ou confirmar valores e normas sobre o "beber bem" - assim como foi verificado por Ancel e Gaussot (1998).

Cumprindo sua função de criar e reforçar identidades sociais (ABRIC, 1994; JODELET, 1999), essas representaçôes promoviam clivagens entre o endogrupo, profissionais de saúde (centrados na biomedicina, membros das classes médias) e exogrupo, usuários (com problemas sociais e psicológicos, membros das classes populares). Intervençôes psicossociais junto aos profissionais de saúde poderiam focar a reconstrução das identidades, de forma a questionar e diminuir essas clivagens. Em consonância com Kanno, Bellodi e Tess (2012), argumenta-se que a formação em saúde dirigida a profissionais de USF deve ser contínua e colaborativa e deve contemplar as produções socioculturais, por exemplo, sobre família, saúde mental, violência e gênero.

Considerar as representações sociais dos atores envolvidos nas práticas de saúde pode contribuir para o atendimento do que Oliveira (2011) chama de "necessidades de saúde", ou seja, das necessidades tais como significadas pelos usuários a partir de uma rede de representações sociais. Levar em consideração crenças e valores das comunidades atendidas é especialmente relevante em contexto de APS.

\section{Considerações finais}

Para concluir, cabe ressaltar que os saberes construídos pelos profissionais no cotidiano não têm como base exclusiva os conhecimentos técnico-científicos e 
que práticas de saúde são práticas sociais. A implantação da Triagem e Intervenção

Breve (AASLAND; NYGAARD; NILSEN, 2008; BRASIL, 2007) e de outras formas de atendimento aos problemas com o álcool no contexto da APS pode se beneficiar de um olhar psicossocial, que esteja atento às relaçôes intergrupais que se estabelecem entre profissionais de saúde e usuários e às representações sociais que são (re)construídas no bojo dessas interações. ${ }^{3}$

\section{Referências}

AASLAND, O. G.; NYGAARD, P.; NILSEN, P. The long and winding road to widespread implementation of screening and brief intervention for alcohol problems. A historical overview with special attention to the WHO initiatives. Nordic studies on alcohol and drugs, Helsinki, v. 25, n. 6, p. 469-476, 2008.

ABRIC, J. C. (Org.). Pratiques sociales et représentations. Paris: PUF, 1994.

ALZUGUIR, F. V. A carreira moral da vergonha na visão de homens e mulheres "alcoólatras". Physis, Rio de Janeiro, v. 24, n. 1, p. 11-29, 2014.

ANCEL, P.; GAUSSOT, L. Alcool et alcoolisme. Pratiques et représentations. Paris: l'Harmattan, 1998.

ANDRADE, T. M.; FRIEDMAN, S. R. Princípios e práticas de redução de danos: interfaces e extensão a outros campos da intervenção e do saber. In: SILVEIRA, D. X.; MOREIRA, F. G. (Org.). Panorama atual de drogas e dependências. São Paulo: Atheneu, 2006. p. 395-400. BARBIANI, R.; JUNGES, J. R.; ASQUIDAMINE, F.; SUGIZAKI, E. Metamorfoses da medicalização e seus impactos na família brasileira. Physis, Rio de Janeiro, v. 24, n. 2, p. 567-587, 2014.

BARDIN, L. Análise de conteúdo. Lisboa: Edições 70, 1977.

BERTOLOTE, J. M. Conceitos em alcoolismo. In: RAMOS, S. P.; BERTOLOTE, J. M. (Org.). Alcoolismo hoje. Porto Alegre: Artes Médicas, 1997. p. 18-31.

BRASIL. Saúde da família: uma estratégia para a reorientação do modelo assistencial. 2 ed. Brasília: Ministério da Saúde, 1998.

BRASIL. A Política do Ministério da Saúde para atenção integral a usuários de álcool e outras drogas. Brasília: Ministério da Saúde, 2004.

BRASIL. Decreto no 6.117, de 22 de maio de 2007. Aprova a Política Nacional sobre o Álcool, dispõe sobre as medidas para redução do uso indevido de álcool e sua associação com a violência e criminalidade, e dá outras providências. Diário Oficial [da] República Federativa do Brasil, Brasília, DF, p. 5, mai. 2007. Seção 1. 
CAMPOS, G. W. S. Saúde Paideia. São Paulo: Hucitec, 2003.

CAMPOS, G. W. S.; DOMITTI, A. C. Apoio matricial e equipe de referência: uma metodologia para gestão do trabalho interdisciplinar em saúde. Cadernos de saúde pública, Rio de Janeiro, v. 23, n. 2, p. 399-407, 2007.

CONRAD, P.; SCHNEIDER, J. W. Deviance and medicalization. From badness to sickness. Philadelphia: Temple University, 1992.

FORMIGONI, M. L. O. S.; MONTEIRO, M. G. A etiologia do alcoolismo. In: RAMOS, S. P.; Bertolote, J. M. (Orgs.). Alcoolismo hoje. Porto Alegre: Artes Médicas, 1997. p. 33-43.

GIOVANELLA, L.; MENDONÇA, M. H. M. Atenção primária à saúde. In: GIOVANELLA, L. et al. (Org.). Politicas e sistema de saúde no Brasil. Rio de Janeiro: Fiocruz, 2008. p. 575-625.

GOLD, M. S.; ADAMEC, C. The encyclopedia of alcoholism and alcohol abuse. New York: Infobase, 2010.

HEATHER, N.; STOCKWELL, T. The essential handbook of treatment and prevention of alcohol problems. Chichester: John Wiley \& Sons, 2004.

JODELET, D. Représentations sociales: un domaine en expansion. In: JODELET, D. (Org.). Les représentations sociales. Paris: PUF, 1999. p. 47-77.

KANNO, N. P.; BELLODI, P. L.; TESS, B. H. Profissionais da Estratégia Saúde da Família diante de demandas médico-sociais: dificuldades e estratégias de enfrentamento. Saúde e sociedade, São Paulo, v. 21, n. 4, p. 884-894, 2012.

MATOS, M. I. S. Meu lar é o botequim. Alcoolismo e masculinidade. São Paulo: Companhia Editora Nacional, 2000.

MOSCOVICI, S. La psychanalyse, son image et son public. Étude sur la représentation sociale de la psychanalyse. Paris: PUF, 1961.

MOSCOVICI, S. Representaçôes sociais. Investigações em psicologia social. Petrópolis: Vozes, 2007.

OLIVEIRA, D. C. A Teoria de Representações Sociais como grade de leitura da saúde e da doença: a constituição de um campo interdisciplinar. In: ALMEIDA, A. M. O.; SANTOS, M. F. S.; TRINDADE, Z. A. (Orgs.). Teoria das representaçôes sociais: 50 anos. Brasília: Technopolitik, 2011. p. 585-623.

POPE, C.; ZIEBLAND, S.; MAYS, N. Analisando dados qualitativos. In: POPE, C.; MAYS, N. (Org.). Pesquisa qualitativa na atenção à saúde, 2 ed. Porto Alegre: Artmed, 2005. p. 87-99. RATINAUD, P. Uma evidência experimental do conceito de representação profissional através do estudo da representação do grupo ideal. Nuances: estudos sobre educação, v. 16, n. 17, p. 135-150, 2009. 
RONZANI, T. M.; FURTADO, E. F. Estigma social sobre o uso de álcool. Jornal brasileiro de psiquiatria, Rio de Janeiro, v. 59, n. 4, p. 326-332, 2010.

ROTGERS, F.; DAVIS, B. A. Treating alcohol problems. New Jersey: John Wiley \& Sons, 2006. SOURNIA, J. C. Histoire de l'alcoolisme. Paris: Flammarion, 1986.

SOUSA, M. F.; HAMANN, E. M. Programa Saúde da Família no Brasil: uma agenda incompleta? Ciência e saúde coletiva, Rio de Janeiro, v. 14, supl. 1, p. 1325-1335, 2009.

\section{Notas}

${ }^{1}$ Sobre equipe matricial, Cf. Campos e Domitti (2007).

${ }^{2}$ Sobre atendimentos típicos de APS, Cf. Giovanella e Mendonça (2008).

${ }^{3}$ L. G. S. Souza participou da concepção da pesquisa, coleta e análise dos dados e redação do artigo. M. C. S. Menandro e P. R. M. Menandro participaram da concepção da pesquisa, interpretação dos dados, revisão crítica do conteúdo intelectual e redação do artigo. Os autores declaram não possuir qualquer conflito de interesse em relação a esta pesquisa. 


\section{Alcoholism, its causes and treatment in the social representations constructed by Brazilian Family Health professionals}

Health sciences define alcoholism as a multifaceted syndrome. Guidelines for treatment include adoption of the harm reduction paradigm and the essential role of Primary Health Care (PHC) towards the wide range of alcohol problems. This research aimed at understanding the social representations of alcoholism constructed by Brazilian PHC professionals, working at Family Health Centers (FHC). We conducted semi-structured interviews with 40 graduated health professionals who worked in 11 different FHC located in a municipality in southeast Brazil. Data were treated with thematic content analysis. We highlight the following results: professionals objectified the alcoholic as a patient who did not search for treatment and/or who threatened the normal functioning of the FHC; professionals considered social and psychological factors as the main causes of alcoholism; they did not mention the concept of harm reduction, nor well-defined treatment protocols. The causal attribution and the representational field inherent to the social representations contributed to anchor alcoholism as a "plague" of poverty. The FHC were perceived simultaneously as important and impotent towards alcoholism. We conclude that the implementation of alcohol-related care strategies must consider the intergroup relations between professionals and patients.

> Key words: alcoholism; social representation; Primary Health Care; Family Health; harm reduction. 